\title{
Seeking a Better Recovery Process from Major Natural Disasters: A Lesson from Several Growth Models with Multiple Equilibria
}

\author{
Kei Hosoya \\ Faculty of Economics, Kokugakuin University, Tokyo, Japan \\ Email: khosoya@kokugakuin.ac.jp
}

How to cite this paper: Hosoya, K. (2017) Seeking a Better Recovery Process from Major Natural Disasters: A Lesson from Several Growth Models with Multiple Equilibria. Theoretical Economics Letters, 7, 1532-1544

https://doi.org/10.4236/tel.2017.75103

Received: July 21, 2017

Accepted: August 21, 2017

Published: August 24, 2017

Copyright $\odot 2017$ by author and Scientific Research Publishing Inc. This work is licensed under the Creative Commons Attribution International License (CC BY 4.0).

http://creativecommons.org/licenses/by/4.0/

\begin{abstract}
Based on several existing growth models with multiple steady states, this paper examines economic conditions that enable recovery from major natural disasters. We focus on recovery from the 2011 Great East Japan Earthquake and Tsunami. More concretely, we survey three recently released studies, which indicate that the sense of direction for expectation formation has the potential to play an important role in recovering from large natural disasters. We also find an inference that the big-push development scenarios that traditionally appear in developing economies have a low affinity with disaster reconstruction in developed countries. After a discussion of these equilibrium selections, this paper makes further reference to economic environments needed for a sustainable recovery path toward a superior long-run, steady-state equilibrium. This equilibrium allows interpreting the terminal of a series of recovery programs in our context.
\end{abstract}

\section{Keywords}

2011 Great East Japan Earthquake and Tsunami, Growth Models, Multiple Equilibria

\section{Introduction}

Natural disasters are an inevitable aspect of life on Earth. Hence, efforts toward disaster prevention and mitigation are obviously important, but there are also other critical issues, such as how to cope in the post-disaster phase and how to make the most of the recovery. The impetus of this paper is the 2011 Great East Japan Earthquake and Tsunami (GEJET), and the aim here is to clarify, to the extent possible, economic requirements for moving an economy heavily damaged by disaster onto a self-reliant recovery track following a series of recovery 
projects.

We take dynamic general equilibrium models as our analytical base. As described in the following section, we focus on several models of economic growth with multiple steady states (i.e., multiple equilibria). For this kind of analytical target, it seems reasonable to assume that differences in recovery policies not only alter the path to recovery, but also distinguish between the long-run steady states (i.e., global multiplicity of equilibrium). ${ }^{1}$ If the possible economic status in the long-term equilibrium is largely different, including the process of transition dynamics, the felicity of a recovery policy would be precisely tested. ${ }^{2}$

Compared with models that cause indeterminacy on only transition paths, there are fewer models involving global indeterminacy. Krugman [1] and Matsuyama [2] are known as pioneering works in this field. ${ }^{3}$ They construct two-sector growth models with increasing returns, and investigate various issues with respect to economic development. Futagami and Mino [3] employ a threshold effect (threshold externality) on public capital, which is also related to our study, and examine various growth patterns. Based on these early contributions, subsequent studies of indeterminacy in a global context have been sporadically published. Raurich-Puigdevall [4] and Brito and Venditti [5] are well-known examples in which one of the sources of multiplicity of equilibrium is examined for various types of externalities. The literature on environmental externalities and economic growth closely explores the present topic, including Pérez and Ruiz [6] and Antoci et al. [7].

The three models of Daitoh [8], Hosoya [9], and Agénor [10] we introduce in this paper can be seen as extensions of these contributions. By examining these models gradually and multilaterally, we hope to extract economic conditions that promote recovery projects. We must first establish an analytical viewpoint for the case of employing a model with multiple equilibria. More specifically, this is related to the "history versus expectations" issue that is symbolically present in the title of Krugman [1]. Regarding an economy's equilibrium selection, the controversial issue of whether history or expectations are more important is a fascinating topic for researchers of macroeconomic dynamics. Meanwhile, our particular case faces the concrete target application of exploring a fruitful recovery process. Therefore, in addition to interest in the equilibrium

\footnotetext{
${ }^{1}$ Note that the models we focus on in this paper are essentially different from standard models with in-determinacy, in which there exist infinitely many transition paths toward a uniquely determined long-run equilibrium where any initial control variable value, including consumption, guarantees convergence to the steady state. This corresponds to local indeterminacy. Another concept for equilibrium indeterminacy is global indeterminacy, in which multiple long-term steady states are possible in a global sense. This is exactly our interest.

${ }^{2}$ This paper does not focus on empirical aspects, but empirical studies and evidence-based analyses are of considerable significance. The Singapore Economic Review (2016, Volume 61, Number 01) recently featured stories of economic crises in disasters. In particular, Okuyama [11] presented an empirical study of the long-term economic effects of the Kobe earthquake using time-series data. His results show that the event generated statistically significant deviations from Kobe's pre-earthquake growth path. This evidences the critical role of recovery policy. For other disaster-related research, see also the literature cited in Hosoya [12] [13].

${ }^{3}$ For further discussion of Krugman [1], see also Fukao and Benabou [14].
} 
(path) selection mechanism, we cannot ignore qualitative implications of the transition dynamics on the selected path; as shown in Hosoya [12] [13] recovery from a severe disaster like the GEJET is a difficult undertaking, regardless of the path taken, and will take a long time. We would like to obtain valuable implications regarding this point through analysis.

In Section 2, starting with Daitoh [8] and followed by Hosoya [9] and then Agénor [10], we carefully examine their implications and present typical phase diagrams under each model. From the issues raised above, solutions are also provided, though still on a modest level. Section 3 summarizes the results of this paper.

\section{A Lesson from the Three Models}

\subsection{Analytical Background}

We consider the possibility that the nature of policies for recovery from major disasters profoundly impact the economy during the recovery period. Considering our present view that policies have a decisive influence on recovery, it seems convenient to regard models with multiple long-term equilibria as an analytical starting point. Also interesting are standard models exhibiting indeterminacy, in which there are infinitely many balanced growth paths toward a uniquely determined long-run equilibrium, but such models have the obvious drawback that the arrival point is the same, regardless of the transition paths passed. Several growth models that allow for diverse long-run situations are easy to understand intuitively, and these are thought to be reasonable frameworks for realistic recovery from disaster.

Regarding the relevancy of the selected models, to first clarify the analytical basis of this paper, Daitoh [8] seems a fairly suitable framework since it provides a single model from which the two contrasting dynamic properties can be obtained. However, that framework focuses on the important role of productive consumption within a developing process in low-income countries, so its application to disaster recovery issues in developed countries like Japan must be performed with care. When taking multiple equilibria as the main target of exploration, it is natural to consider public infrastructure and its external effects as a force shaping the outcome. Specifically, recovery from massive disaster corresponds to the process of rebuilding lost infrastructure. Hosoya [9] and Agénor [10] provide models that include these factors.

We start with Daitoh [8] to clarify our analytical viewpoint. Then, by additionally examining Hosoya [9] and Agénor [10], which have characteristics different from Daitoh [8], we further address the targeted issue.

\subsection{Daitoh [8] Model}

In Daitoh [8], since distinct patterns involving multiple steady states are possible within an identical framework, it is useful to know the present issue. One is the situation in which a "big push" has a critical impact on the economy's equilibrium selection. Another is the situation in which the direction of the agent's 
self-fulfilling expectations has a vital role. In particular, as seen from the fact that the issue of big push is raised in graduate-level textbooks such as Barro and Sala-i-Martin [15], this involves fundamental problems for economic development such as escaping poverty traps. As for the role of expectations, many recent studies of indeterminacy consider this factor, with Benhabib and Farmer [16] and Benhabib and Perli [17] sparking a boom. When the case in which economic fundamentals yield multiple equilibria and the presence or absence of a big push at the levels of physical capital and infrastructure characterizes the long-run status is compared with the case in which self-fulfilling expectations influence equilibrium selection, we see that their implications for recovery policy differ considerably. A gap between the two is thus inevitable.

Let us briefly outline Daitoh [8]. This model extends that of Benhabib and Farmer [16], which considered capital and labor externalities and permitted elastic labor supply by introducing an element of productive consumption posited in development economics. The productive consumption in Daitoh [8] posits that the effect of an increase in consumption per worker $c_{t}$ contributes labor productivity $h\left(c_{t}\right)$, and therefore implies that $h^{\prime}\left(c_{t}\right)>0 .{ }^{4}$ As can be presumed from existing studies of indeterminacy, complex dynamics depending on the degree of externality and the impact of productive consumption are possible, and such are seen in the model of Daitoh [8].

We first examine a case in which emphasis is on the role of big push. This is possible in cases of mild labor externality and a relatively large productive consumption effect. Figure 1 shows a typical case. In that figure, the horizontal axis is the capital level and the vertical axis is the imputed price of capital, which implies the inverse consumption level $(1 / c)$. On the $(k, p)$-plane, the three steady states can be confirmed. $E_{1}$ and $E_{3}$ are stable saddle-point equilibria, while $E_{2}$ is an unstable (source) equilibrium. Regarding the two stable equilibria, we can deem $E_{3}$ as the superior equilibrium from the viewpoint of capital accumulation.

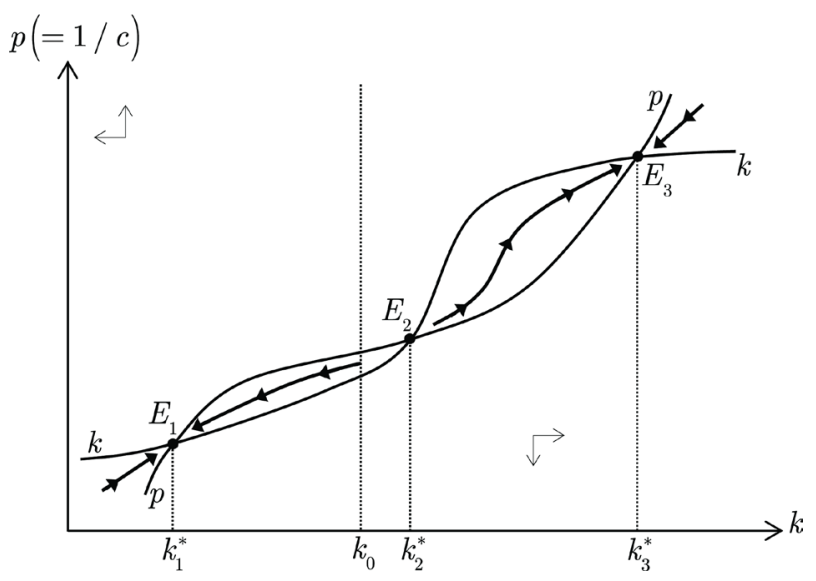

Figure 1. Multiple equilibria and big push in Daitoh [8].

${ }^{4}$ Hence, if $n_{t}$ is hours worked, $N_{t}=h\left(c_{t}\right) n_{t}$ represents the labor supply of efficiency unit per worker. 
In this situation, a transition path is uniquely determined independently of the initial value for capital $k_{0}$. For this reason, in the case of declining capital levels due to a major natural disaster, war, poverty trap, etc., leading the economy to the superior equilibrium $E_{3}$ through economic growth requires a fairly large initial social investment exceeding the boundary level $k_{2}^{*}$; this is the so-called "big push". Alternatively, since initial conditions (historical backgrounds) predetermine whether the economy proceeds to $E_{1}$ or $E_{3}$ or stays fixed at $E_{2}$, the present case seems to correspond to the situation where historical factors have a critical impact on equilibrium selection. ${ }^{5}$ As noted, this situation is possible in the case of larger productive consumption effects and therefore is just the case of developing countries falling into a poverty trap. In contrast, in a major disaster the influence of productive consumption would be limited to the case of developed countries with mature economies.

Remark 1. Big-push models in which the effect of productive consumption is strong and historical factors influence the fate of the economy are unsuitable mental models for recovery processes.

In addition, in Daitoh [8], even if the productive consumption effect is relatively small, other interesting dynamics can be obtained. We examine this case next.

Figure 2 shows a case where both labor externality and productive consumption are small. As in Figure 1, the long-run equilibrium $E_{1}$ and $E_{3}$ exhibit saddle-path stability. Noting that this figure is represented in the $(k, 1 / c)$-plane, as in the case above, we can interpret $E_{1}$ and $E_{3}$ as the inferior equilibrium and superior equilibrium, respectively ( $E_{2}$ is an unstable equilibrium). This case implies an interesting situation regarding dynamics: regardless of the economy's initial level of capital stock, one can select a transition path converging to either long-run equilibrium $E_{1}$ or $E_{3}$, depending on the direction of the agent's self-fulfilling expectations.

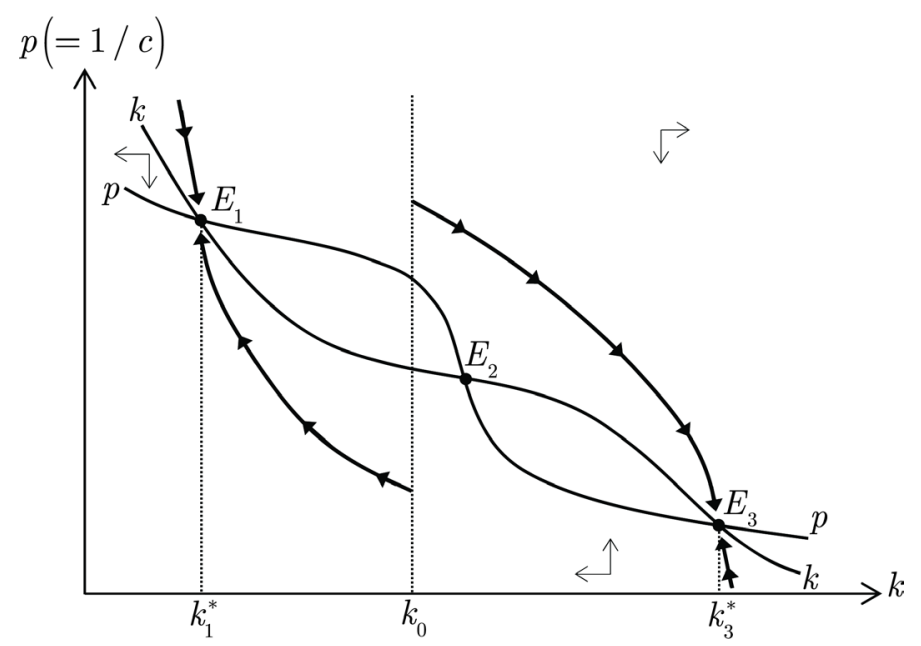

Figure 2. Multiple equilibria and self-fulfilling expectations in Daitoh [8].

${ }^{5}$ To realize $E_{2}$, the economy is limited to $E_{2}$ at the initial point. 
Let us interpret the theoretical implications of this from the viewpoint of recovery policy. First, if actual policy is inconsistent with expectations, then recovery policies including reconstruction and enhancement for public capital, which will begin immediately after a major disaster, do not necessarily ensure good performance in the long run. A coordination failure of expectations can cause the economy to become stuck at the inferior equilibrium $E_{1}$. In contrast, shared expectations enable the economy to follow the high-growth path, independent of history. More concretely, by realizing $E_{3}$, one expects the economy to transition to the path toward $E_{3}$ and actually realizing the long-run steady state of $E_{3}$.

The above suggests that policies excessively oriented toward support for consumption activities of victims have the potential to yield undesirable results in the medium- and long-run, if not the time immediately after a disaster. With an eye to the future, a balance between consumption and saving (or investment) supporting a self-reliant recovery path is important. If successful, the economy enters the saddle path extending to the lower right and thus is more likely to achieve the superior equilibrium $E_{3}$.

Remark 2. The proposed model, which is characterized by low productive consumption and small labor externalities, is a suitable framework for depicting recovery processes. In this model, expectations determine long-term equilibria. The model also shows the possibility that recovery policies addressing livelihood support for victims become fetters if extended over a long period of time.

\subsection{Hosoya [9] Model}

The following describes the model of Hosoya [9], which considers public infrastructure with the standard optimal growth model as the development device. Public infrastructure affects both utility and production functions, and the emergence of multiple steady states is shown to depend on the magnitude of the elasticity of intertemporal substitution. Figure 3 shows a typical pattern of the

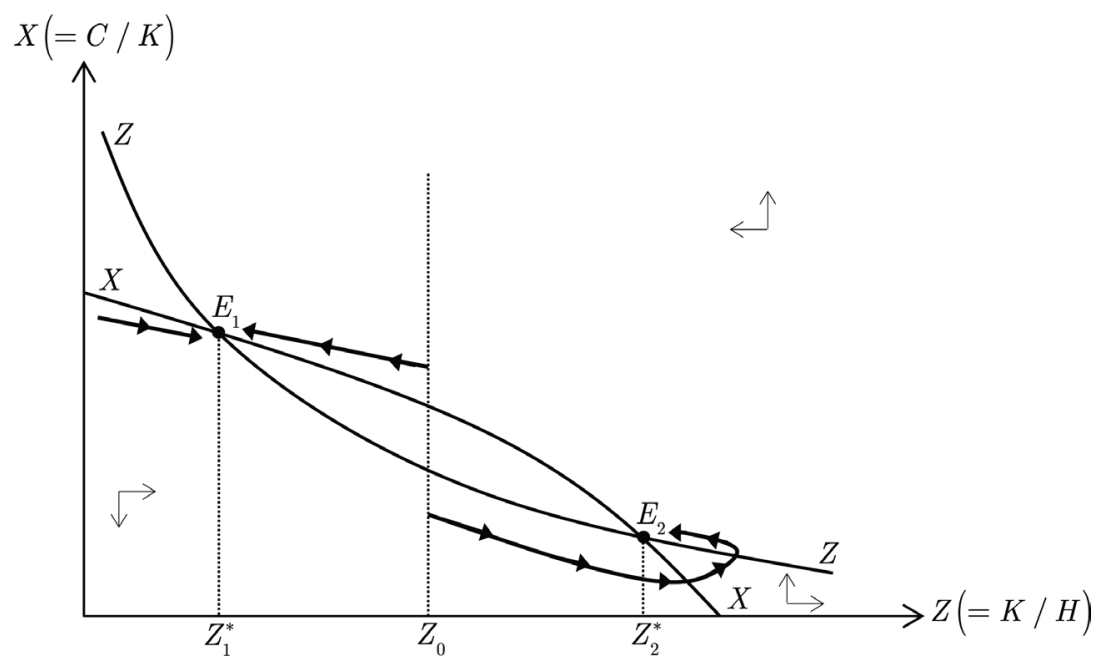

Figure 3. Multiple equilibria and self-fulfilling expectations in Hosoya [9]. 
dynamics. ${ }^{6}$ There are two steady states in this model. It is interesting that each equilibrium has a distinct property with respect to the dynamics. From the viewpoint of the growth rate, the inferior equilibrium $E_{1}$ exhibits saddle-point stability, while the superior equilibrium $E_{2}$ presents indeterminacy.

The equilibrium selection mechanism in this model is not a historical path dependency, but rather self-fulfilling expectations, as clearly shown in Figure 3. Let us focus on $Z_{0}$, which represents the initial value of the ratio of private capital to public infrastructure. The long-run equilibrium is not constrained to this value. In other words, it is not constrained to history. As a result, we find that the direction of expectations governs a realizing long-run equilibrium. Along the lines of Daitoh [8], the model of Hosoya [9] is similar to the case of Figure 2. ${ }^{8}$

The implications of this model allowing for recovery from disaster are as follows. Roughly speaking, there are the two required conditions for a recovery policy aiming for the high-growth equilibrium $E_{2}$. One is creating a situation where positive expectations dominate the economy through public-private cooperation. In this respect, confidence in politics and government is essential. The other is a more concrete condition: to enter the transition path toward $E_{2}$, the economy needs to select a relatively lower level of $X$ at the initial point $X_{0} \cdot{ }^{9}$ This implies that to aim at $E_{2}$ from a given $K_{0}$, the economy should feature discreet excessive consumption. Economic activities that overly prioritize consumption may increase the risk that the economy will be directed toward the low-growth equilibrium $\left(E_{1}\right)$.

For a better recovery process as evaluated from an economic viewpoint, multiple equilibria models can confirm the importance of investment through savings. Let us concretely confirm this point by representing part of the numerical analysis in Hosoya [9]. Table 1 summarizes the economic status at each long-run steady state, which clearly shows that optimistic agent expectations concerning infrastructure provision promote capital accumulation through active investment and lead the economy to a high-growth equilibrium $\left(E_{2}\right)$. At this stage, the superior equilibrium corresponds to a long-run situation leading to a better recovery process.

${ }^{6}$ Hosoya [9] refers to and analyzes the local dynamics property of the proposed model, examining global dynamics for the first time. Hosoya [9] discussed the general case of $\alpha \neq \theta$, but here we consider Figure 3 under the condition $\alpha=\theta$ to enable global dynamics analysis, where $\alpha$ and $1 / \theta$, respectively denote the share of physical capital in goods production and the intertemporal elasticity of substitution.

${ }^{7}$ Hosoya [9] applies this pair of equilibrium properties to the interpretation of the famous growth episodes of South Korea and the Philippines, as introduced by Lucas [18]. More specifically, it is argued that the Philippines has experienced a standard steady-growth path, approximated by a growth path with saddle-path stability, whereas South Korea exemplifies a growth miracle approximated by a growth path with indeterminacy.

${ }^{8}$ Note, however, that the dynamic property of each equilibrium is different between these models. In Daitoh [8], the case of an indeterminate equilibrium path is possible, but the long-run steady state itself is uniquely determined.

${ }^{9}$ As clearly seen from Figure 3, for a given $Z_{0}$, the level of $X_{0}$ corresponding to the case of $E_{2}$ is surely at a low level as compared to the initial level of $X$ on the equilibrium path converging to $E_{1}$. 
Table 1. A numerical example in Hosoya [9].

\begin{tabular}{ccc}
\hline & $E_{1}$ & $E_{2}$ \\
\hline Growth rate (\%) & 2.04 & 3.03 \\
Consumption/GDP $(C / Y)$ & 0.872 & 0.736 \\
Private investment/GDP $(\dot{K} / Y)$ & 0.103 & 0.239 \\
Public investment/GDP $(\dot{H} / Y)$ & 0.010 & 0.012 \\
\hline
\end{tabular}

Source: Hosoya [9].

These findings by Hosoya [9] have similar implications for recovery policy to those by Daitoh [8]. A certain level of savings is indispensable toward setting a recovery path. Therefore, the economy (government) needs to promote recovery policies that balance consumption and savings. Based on these two models with multiple equilibria in which self-fulfilling expectations play a vital role in equilibrium selection, the following pertains to policies for guidance to recovery:

Remark 3 ([8] [9]). To improve the probability of the economy arriving at the high-growth equilibrium through promoting recovery policy, it is essential to maintain a balance between consumption and savings with due consideration of the formation of agent expectations.

In the context of this paper, such equilibria correspond to situations where a disaster-affected economy experiences a better recovery process.

\subsection{Agénor [10] Model}

In this section, we investigate Agénor [10], which has features that differ from the previous two models. This model includes publicly provided infrastructure, and it acts as an engine for long-term development, making it suitable for exploring the future of developing countries. The government also bears health service expenditures, which contribute to boosting labor productivity. Moreover, the model considers network externalities generated by infrastructure itself and implements nonlinearity relevant to the impact of infrastructure on the economy (i.e., threshold effects). In this model, one can obtain the intriguing result that the two contrasting mechanisms of history and expectations in equilibrium selection noted above coexist, and both mechanisms are possible depending on the level of the public-private capital ratio $\left(k_{I}\right)$. Note that the two economically meaningful equilibria have a saddle-point stability. That is, infinitely many equilibrium growth paths can be allowed until the economy enters a saddle path, after which a path toward long-term equilibrium is uniquely determined. Figure 4 represents a possible situation of this model.

Referring to Agénor [10] for details on dynamics, let us here outline our view-point. In Figure 4, $E_{1}$ and $E_{3}$ of the three steady states are stable, whereas $E_{2}$ is unstable. With respect to the growth rate, $E_{1}$ and $E_{3}$ are respectively the inferior and superior equilibrium. As to the level of $E_{1}$ set in the horizontal axis, we are able to perform zone division for patterns of dynamics. When the 


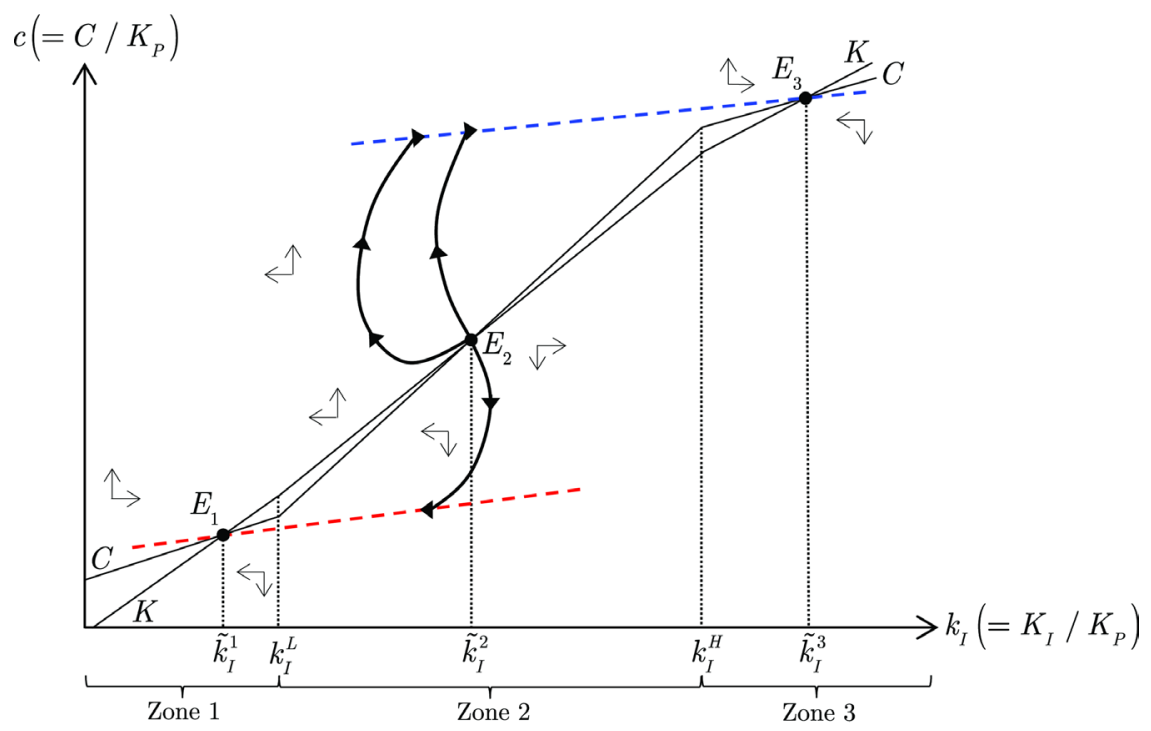

Figure 4. Multiple equilibria including several dynamics in Agénor [10].

initial value of $k_{I}$ lies in Zone 1, the economy arrives at $E_{1}$ via the red dotted-line saddle path. Viewed from development theory, $E_{1}$ seems to correspond to the situation of a poverty trap (an underdevelopment trap or low-growth trap). The same goes for the case of Zone 3. When the initial value of $k_{I}$ lies in Zone 3, the economy arrives at $E_{3}$ via the blue dotted-line saddle path. In these zones, the initial value of the capital ratio (namely, the historical background) determines the long-term status of the economy. So, for example when $k_{I}^{0}$ lies in $\tilde{k}_{I}^{1}<k_{I}^{0}<k_{I}^{L}$, if the economy tries to achieve the high-growth equilibrium $E_{3}$, significant social investment is required to get into Zone 3. In other words, the economy calls for a big push.

However, when the initial value of the capital ratio lies in Zone 2, the situation greatly varies. It is more likely that the economy smoothly converges to each equilibrium via the saddle path or through self-fulfilling expectations governing the future, as on both sides (Zones 1 and 3) of the present zone. More concretely, given the stock variable $k_{I}$, the equilibrium $E_{3}$ is possible if the agent has optimistic expectations and selects a corresponding consumption level. In contrast, $E_{1}$ is possible if the agent has pessimistic expectations. ${ }^{10}$ These correspond to the case of self-fulfilling expectations. As a result, in Zone 2 it is highly likely that the direction of agent expectations dictates the arrival to a long-run steady state independently of historical background (i.e., $k_{I}^{0}$ ).

As described, the model of Agénor [10] is a hybrid model of history and expectations. However, considering the viewpoint of recovery policy we focus on in this paper, the present model provides important implications differing from those of the previous two models. Reconsidering Figure 4, note that $c$, which is placed on the vertical axis, corresponds to the consumption-capital ratio $\left(C / K_{P}\right)$. Entering the blue dotted-line equilibrium growth path that leads to $E_{3}$ in Zone 2, optimistic expectations are a consequent prerequisite. In addition,

${ }^{10}$ The three reference paths are shown in Figure 4. 
the overall economy needs to select a relatively high consumption level at the initial point in time. We summarize this as follows:

Remark 4. In Agénor [10], when expectations play a vital role in equilibrium selection under multiple equilibria, the economy must initially select a high consumption level to enter a transition path converging to a high-growth equilibrium.

Comparing this with the results of standard growth theory and of the previous two models, Agénor [10] provides a characteristic result. In the context of recovery issues, Figure 4 implies the importance of the economy selecting a higher consumption level, not only in the period immediately after the disaster but also in subsequent stages of the recovery process. Applying this result to our analytical interest suggests that the key to successful recovery is the economy first aspiring for the highest possible consumption level in the early stages of recovery, then entering a growth path toward high-growth equilibrium.

In general, aggressive and productive investment that accommodates savings is required for sustainable growth. To that end, intertemporal substitution in consumption plays a vital role. But, as shown above, creating multiple steady states as in Agénor [10] requires a certain background. Concretely, with respect to the degree of efficiency from public infrastructure, Agénor [10] employs threshold effects along the lines of Futagami and Mino [3]. In the case of multiple equilibria, sufficiently strong external effects are required. It is easy to imagine that public infrastructure exerts a strong network externality only when accumulated at a certain level. The corresponding stages of development would thus exceed a certain level. ${ }^{11}$

Though we would like to present a clear-cut view from a phase analysis like that in Figure 4, Agénor [10] may be suitable for explaining the bifurcation in a developed economy in which the distance between two stable equilibria is close and the corresponding capital level $\tilde{k}_{I}^{1}$ already achieves a certain level, even in the case of a low-growth equilibrium. Also, as an alternative view, the equilibrium path toward $E_{3}$ seems to exemplify the more rapid growth that is experienced by less developed countries in the course of becoming developed. These findings cast the model of Agénor [10] into doubt as a model depicting a recovery process.

Remark 5. From the considerations above, Agénor [10] is not suitable as a device for disaster research in developed countries.

\subsection{Key Implications from the Analysis}

Regardless, when considering a situation where the economy (government) successfully coordinates agent expectations and then aims for a superior steady-state equilibrium as the terminal recovery process, there are obvious differences between the Daitoh and Hosoya models and the Agénor model regarding their implications, even though both yield multiple equilibria. According to the above considerations, by fully examining the envisioned economic and social status,

\footnotetext{
${ }^{11}$ Note that Agénor [10] assumed developing countries when formulating his model.
} 
the results from Daitoh [8] and Hosoya [9] seem to be particularly useful as a guiding principle for disaster recovery. Assuming the disaster area as a closed economy, if the economy tries to realize a better recovery process by itself, the key to success is in intertemporal substitution of consumption. ${ }^{12}$ Hence, in addition to consumption, policy management that considers the flow from savings to investment is needed to support a strong recovery. For example, preferential treatment for investment in the disaster area is an important policy instrument. On reflection, this implication resembles the message from the standard growth models and is applicable to the case of models with multiple steady states. All the same, we must proceed while keeping in mind that there is no easy path to recovery.

\section{Concluding Remarks}

We surveyed recent characteristic models with multiple equilibria and intended to obtain economic implications regarding recovery from major natural disasters like the GEJET. From the complexity of the model with multiple equilibria, it is undeniable that our assertion is model-oriented to some extent. However, through examination of Daitoh [8] we confirmed that a model with self-fulfilling expectations characterizing equilibrium selection is a suitable framework for describing a recovery path from disaster.

Then, though the properties related to long-run stable equilibria are different, we found that Hosoya [9] is similar to Daitoh [8] in that it is the direction of expectations, rather than historical background, that determines the arrival equilibrium. A common finding in these models is that intertemporal resource allocation between consumption and savings (investment) plays an important role in leading the economy to a better recovery process. With the exception of the period immediately after the disaster, recovery projects should consider mid- and long-term perspectives by not over-emphasizing consumption.

Also, Agénor [10] provided an important finding. Most notable are cases where expectations play a vital role in equilibrium selection, as with Daitoh [8] and Hosoya [9]. To arrive at the superior equilibrium, Agénor [10] naturally required optimistic agent expectations, as do Daitoh [8] and Hosoya [9]. Agénor [10], however, is remarkable in that a high-growth equilibrium is possible by the economy continually selecting higher consumption levels from the initial time (in the context of this paper, since the start of recovery projects). Accordingly, in this model, consumption stimulates sustainable growth. This is extremely interesting as a theory of macroeconomic dynamics, but feels odd as a theoretical framework representing the overall recovery process from natural disasters.

This paper seems to partially show how transition processes are desired to acquire mid- and long-term results through recovery policy. Considering the

\footnotetext{
${ }^{12}$ In fact, the disaster area is not a closed economy; it will receive support from the public and private sectors of other areas. Given this envisioned situation, we focus only on intrinsic recovery of the disaster area. Therefore, for instance, if various support measures including the recovery project by the central government fit together with (optimistic) agent expectations, that would create a likely scenario where the economy easily enters a high-growth equilibrium path.
} 
status in the coastal district of the disaster area, large, wide-scale public recovery projects have been strongly promoted. An important remaining task is further investigation of how such development is evaluated according to the models examined in this paper. In particular, we have indirectly clarified the importance of capital and infrastructure accumulation, but these will contribute to the recovery process only if adequately leveraged. Many disaster areas in Japan are experiencing population outflow and aging, so the modality of recovery project needs to be examined from various perspectives.

\section{Acknowledgements}

The author thanks an anonymous referee and the participants of the $2017 \mathrm{Fa}$ culty Workshop at Kokugakuin University for their valuable comments. The author also thanks Kazumi Asako, Masakatsu Nakamura, Takashi Kano, Yoshinobu Matsui, Akiyuki Tonogi, and Gang Li for their helpful comments and suggestions on Hosoya [9] on which the present paper depends. This work was financially supported by Grants-in-Aid for Young Scientists (B) 24730251 and for Scientific Research (C) 15K03448 from the Japan Society for the Promotion of Science. Any remaining errors are my own responsibility.

\section{References}

[1] Krugman, P. (1991) History versus Expectations. The Quarterly Journal of Economics, 106, 651-667. https://doi.org/10.2307/2937950

[2] Matsuyama, K. (1991) Increasing Returns, Industrialization, and Indeterminacy of Equilibria. The Quarterly Journal of Economics, 106, 617-650. https://doi.org/10.2307/2937949

[3] Futagami, K. and Mino, K. (1995) Public Capital and Patterns of Growth in the Presence of Threshold Externalities. Journal of Economics, 61, 123-146.

https://doi.org/10.1007/BF01238777

[4] Raurich-Puigdevall, X. (2000) Global Indeterminacy in an Endogenous-Growth Model with Public Capital. Journal of Economics, 71, 255-280. https://doi.org/10.1007/BF01228743

[5] Brito, P. and Venditti, A. (2010) Local and Global Indeterminacy in Two-Sector Models of Endogenous Growth. Journal of Mathematical Economics, 46, 893-911. https://doi.org/10.1016/j.jmateco.2010.08.003

[6] Pérez, R. and Ruiz, J. (2007) Global and Local Indeterminacy and Optimal Environmental Public Policies in an Economy with Public Abatement Activities. Economic Modelling, 24, 431-452. https://doi.org/10.1016/j.econmod.2006.10.004

[7] Antoci, A., Galeotti, M. and Russu, P. (2011) Poverty Trap and Global Indeterminacy in a Growth Model with Open-Access Natural Resources. Journal of Economic Theory, 146, 569-591. https://doi.org/10.1016/j.jet.2010.12.003

[8] Daitoh, I. (2012) A Growth Model of Human Development: Productive Consumption Hypothesis and Indeterminacy of Equilibrium. Unpublished Manuscript, Tohoku University (in Japanese).

[9] Hosoya, K. (2017) Accounting for Growth Disparity: Lucas's Framework Revisited. Review of Development Economics, 21, 874-887.

https://doi.org/10.1111/rode.12297 
[10] Agénor, P.-R. (2010) A Theory of Infrastructure-Led Development. Journal of Economic Dynamics and Control, 34, 932-950. https://doi.org/10.1016/j.jedc.2010.01.009

[11] Okuyama, Y. (2016) Long-Run Effect of a Disaster: Case Study on the Kobe Earthquake. The Singapore Economic Review, 61, Article ID: 1640009. https://doi.org/10.1142/S0217590816400099

[12] Hosoya, K. (2015) Importance of a Victim-Oriented Recovery Policy after Major Disasters. TGU-ECON Discussion Paper Series \#2015-3, Tohoku Gakuin University.

[13] Hosoya, K. (2016) Recovery from Natural Disaster: A Numerical Investigation Based on the Convergence Approach. Economic Modelling, 55, 410-420. https://doi.org/10.1016/j.econmod.2016.02.029

[14] Fukao, K. and Benabou, R. (1993) History versus Expectations: A Comment. The Quarterly Journal of Economics, 108, 535-542. https://doi.org/10.2307/2118344

[15] Barro, R.J. and Sala-i-Martin, X. (2003) Economic Growth. 2nd Edition, MIT Press, Cambridge.

[16] Benhabib, J. and Farmer, R.E. (1994) Indeterminacy and Increasing Returns. Journal of Economic Theory, 63, 19-41. https://doi.org/10.1006/jeth.1994.1031

[17] Benhabib, J. and Perli, R. (1994) Uniqueness and Indeterminacy: On the Dynamics of Endogenous Growth. Journal of Economic Theory, 63, 113-142. https://doi.org/10.1006/jeth.1994.1035

[18] Lucas Jr., R.E. (1993) Making a Miracle. Econometrica, 61, 251-272. https://doi.org/10.2307/2951551

\section{Submit or recommend next manuscript to SCIRP and we will provide best service for you:}

Accepting pre-submission inquiries through Email, Facebook, LinkedIn, Twitter, etc. A wide selection of journals (inclusive of 9 subjects, more than 200 journals)

Providing 24-hour high-quality service

User-friendly online submission system

Fair and swift peer-review system

Efficient typesetting and proofreading procedure

Display of the result of downloads and visits, as well as the number of cited articles

Maximum dissemination of your research work

Submit your manuscript at: http://papersubmission.scirp.org/

Or contact tel@scirp.org 